\title{
Seasonal influence on polar cap patches in the high-latitude nightside ionosphere
}

\author{
A. G. Wood ${ }^{1}$ and S. E. Pryse ${ }^{1}$ \\ Received 13 October 2009; revised 3 December 2009; accepted 4 January 2010; published 15 July 2010.
}

[1] The influence of the season on the patch-to-background density ratio of polar cap patches in the nightside ionosphere was observed above northern Scandinavia around solar maximum (1999-2001). This is the first study of the seasonal effect in the nightside polar ionosphere. The observations were conducted by the European Incoherent Scatter Svalbard Radar under conditions favorable for patches based on the high-latitude plasma convection pattern, the interplanetary magnetic field, and an absence of in situ precipitation. Patch-to-background ratios of up to $9.4 \pm 2.9$ were observed between midwinter and equinox, with values of up to $1.9 \pm 0.2$ in summer. As the patch-to-background ratios in summer were $<2$, the enhancements could not formally be called patches; however, these were significant density enhancements within the antisunward cross-polar flow. Aberystwyth University's PLASLIFE (PLASma LIFEtime) computer simulation was used to model the observed seasonal trend in the patch-to-background ratio and to establish reasons for the difference between winter and summer values. This difference was primarily attributed to variation in the chemical composition of the atmosphere, which, in summer, both reduced the electron densities of the plasma drawn into the polar cap on the dayside and enhanced plasma loss by recombination. A secondary factor was the maintenance of the background polar ionosphere by photoionization in summer.

Citation: Wood, A. G., and S. E. Pryse (2010), Seasonal influence on polar cap patches in the high-latitude nightside ionosphere, J. Geophys. Res., 115, A07311, doi:10.1029/2009JA014985.

\section{Introduction}

[2] The ionospheric plasma in the polar cap is structured on a wide range of horizontal spatial scale sizes [Tsunoda, 1988]. Of particular interest in the present study are large-scale electron density enhancements in the $F$ region known as polar cap patches. These were defined by Crowley [1996] to have a horizontal extent of at least $100 \mathrm{~km}$, plasma densities at least twice that of the surrounding background ionosphere, and, thus, a patch-to-background ratio of $\geq 2$. Early observations of polar cap patches were made using an all-sky photometer and an ionosonde, both located close to the geomagnetic pole at Thule, Greenland $\left(77.5^{\circ} \mathrm{N}, 69.2^{\circ} \mathrm{W} ; 85.4^{\circ}\right.$ magnetic latitude (MLAT), $32.4^{\circ}$ magnetic longitude (MLON)) [Buchau et al., 1983]. In this study the patches were seen to convect antisunward with the background plasma flow. It was subsequently proposed that they were produced on the dayside at auroral or subauroral latitudes and then convected antisunward to higher, polar latitudes [Weber et al., 1984]. Average maps of the ionospheric convection flows and electron density from the Chatinka incoherent scatter radar also suggested solar-produced plasma being drawn into the polar cap on the dayside [Foster, 1984]. Observations indicated that the patches could be transported over large distances and an indi-

\footnotetext{
${ }^{1}$ Aberystwyth University, Aberystwyth, United Kingdom.
}

Copyright 2010 by the American Geophysical Union. 0148-0227/10/2009JA014985 vidual patch has been followed for more than $3000 \mathrm{~km}$ from the center of the polar cap to the poleward edge of the nightside auroral oval [Weber et al., 1986]. The Utah State University Time-Dependent Ionospheric Model (TDIM) has been used to show that the plasma can traverse the entire polar cap [Sojka et al., 1994]. Robinson et al. [1985] modeled a patch drifting out of the polar cap, which was reconfigured to form a boundary blob in the nightside auroral oval. Subsequent observations have shown patches drifting out of the polar cap [Pedersen et al., 2000] and being reconfigured to form a boundary blob [Pryse et al., 2006].

[3] Polar cap plasma exhibits seasonal variation. This was first observed using the Chatinka incoherent scatter radar, where dayside plasma densities drawn into the polar cap were three times greater in winter than in summer [Foster, 1984]. A similar seasonal pattern of higher winter densities had previously been reported at midlatitudes by Risbeth and Setty [1961] and Wright [1963]. The authors attributed this to the seasonal anomaly where higher temperatures caused upwelling of the thermosphere in the summer hemisphere. This led to lower $\mathrm{O} /\left[\mathrm{N}_{2}\right]$ and $\mathrm{O} /\left[\mathrm{O}_{2}\right]$ atomic/molecular ratios, which increased chemical recombination and consequently decreased the plasma density. The seasonal variation of polar cap plasma at high latitudes was modeled by Schunk and Sojka [1987] and the physical processes driving the change investigated. In this study a patch of electron density 10 times higher than the background was introduced to the highlatitude convection pattern close to the geomagnetic pole, and 
the time taken for the density to decay to $10 \%$ above the background was calculated. This was $4 \mathrm{~h}$ in summer and $11 \mathrm{~h}$ in winter. The primary physical reason for this difference was the maintenance of background densities in summer by solar EUV radiation. In winter the background densities decayed with the same time constant as the patches. A secondary reason was increased recombination rates in summer, resulting from increased ion temperatures and differences in the composition of the thermosphere.

[4] Seasonal differences in polar cap plasma were subsequently observed and modeled at specific locations. Observations conducted near the geomagnetic pole at Qaanaaq, Greenland $\left(78.6^{\circ} \mathrm{N}, 289.9^{\circ} \mathrm{E} ; 86.7^{\circ} \mathrm{MLAT}, 40.4^{\circ} \mathrm{MLON}\right)$, showed significantly higher patch-to-background ratios in winter than in summer, with values of 10 and 3, respectively [Buchau and Reinisch, 1991]. In a separate modeling study Sojka et al. [1994] obtained the patch-to-background ratio at 2300 magnetic local time (MLT) and $80^{\circ}$ MLAT using simulation studies where a continuous plasma enhancement drawn into the polar cap was broken into a series of patches by instantaneously switching between two convection patterns. The modeled patch-to-background ratio was up to 3 in winter but only a few tenths of a percent above the background at midsummer. These summer enhancements were below the level expected to be detectable in observational studies. Simulations of the patch-to-background ratios at $\mathrm{Ny}-$ Ålesund $\left(78.9^{\circ} \mathrm{N}, 12.0^{\circ} \mathrm{E} ; 76.0^{\circ} \mathrm{MLAT}, 112.3^{\circ} \mathrm{MLON}\right)$ also predicted that enhancements would fulfill the criteria for patches in winter but be indistinguishable from the background in summer [Bowline et al., 1996]. A statistical study of 225 patches observed in the northern polar cap by the Dynamics Explorer 2 spacecraft [Coley and Heelis, 1998] supported these modeling results and showed that patches were largely a winter phenomena, with the patch and background levels frequently indistinguishable when the polar cap was sunlit.

[5] Polar cap plasma is also influenced by the solar wind conditions. A statistical study close to the geomagnetic pole showed that patches were primarily associated with times when interplanetary magnetic field (IMF) $B_{z}$ was negative [McEwen and Harris, 1996]. This was attributed to the convection pattern under these conditions being favorable for the antisunward cross-polar transport of plasma. However, $20 \%$ of the patches observed occurred during IMF $B_{z}$ positive. Closer inspection of the latter group showed that, in most of the cases, IMF $B_{z}$ either was close to zero or had become positive within $2 \mathrm{~h}$ prior to the observation. It was therefore suggested that the patches associated with IMF $B_{z}$ positive had entered the polar cap during conditions of IMF $B_{z}$ negative. This result was supported by observations of plasma in the nightside ionosphere using the European Incoherent Scatter (EISCAT) Svalbard Radar (ESR), where plasma observed during IMF $B_{z}$ positive was shown to have crossed the solar terminator in the polar region when IMF $B_{z}$ was negative [Wood et al., 2008]. This study also illustrated crosspolar transport under IMF $B_{z}$ positive when IMF $\left|B_{y}\right| \gg\left|B_{z}\right|$. Variation in IMF $B_{y}$ also alters the high-latitude convection pattern [Reiff and Burch, 1985] and is likely to affect the MLT at which an individual patch occurs. However, a statistical by Moen et al. [2007] that used 8 years of meridian scanning photometer data in the nightside ionosphere showed that, when all cases of IMF $B_{y}$ positive and negative were taken collectively, then the distribution of patches was symmetric around 2325 MLT. Comparison of this result with the statistical flow patterns of Ruohoniemi and Greenwald [2005] indicated that patches did not preferentially originate from either the dawn or the dusk cell. This result was consistent with simulations by Bowline et al. [1996] showing that modification of the convection pattern by changes in IMF $B_{y}$ did not affect the presence of polar cap patches in the nightside ionosphere but did alter the MLT at which individual patches occurred.

[6] The solar cycle is another influence on the patch-tobackground ratio. Simulations predicted that patch lifetimes would be longer at solar maximum than at solar minimum, with this difference attributed to changes in the solar EUV radiation intensity [Schunk and Sojka, 1987]. Around solar maximum winter nightside patches were observed using the Sondrestrom incoherent scatter radar [Pedersen et al., 1998]. The majority of patch-to-background ratios were between 2 and 4, although values as high as 9 were recorded.

[7] This paper presents observations of polar cap plasma in the nightside ionosphere between winter and equinox and in summer. Previous observational studies have discussed this seasonal effect in other regions of the polar cap. However, the present study is the first to investigate this effect in the nightside polar ionosphere. This region is particularly significant as it is the sector of the polar cap containing patches that have been transported farthest from their source and have had the longest decay time. The physical processes driving the seasonal change are investigated using Aberystwyth University's PLASLIFE (PLASma LIFEtime) simulation to establish their relative importance.

\section{Instrumentation and Simulation}

[8] Measurements of electron density and temperature were made by the $32 \mathrm{~m}$ dish of the EISCAT ESR [Wannberg et al., 1997] and the $42 \mathrm{~m}$ dish of the facility, both located at $78.2^{\circ} \mathrm{N}, 16.0^{\circ} \mathrm{E}, 75.2^{\circ} \mathrm{MLAT}, 112.9^{\circ} \mathrm{MLON}$, at Longyearbyen on Svalbard. Line-of-sight plasma velocities in the $F$ region were observed by the Super Dual Auroral Radar Network (SuperDARN), comprising eight high-latitude coherent scatter radars in the Northern Hemisphere and six in the Southern Hemisphere [Greenwald et al., 1995; Chisham et al., 2007]. These Northern Hemisphere measurements were used to infer the high-latitude electric potential patterns using the spherical harmonic fitting technique of Ruohomiemi and Baker [1998]. The plasma convection patterns were directly inferred from the electric potential maps, with the plasma in the $F$ region transported along equipotential contours under the $E \times B$ drift. The solar wind was monitored at the Lagrangian L1 point by the Advanced Composition Explorer (ACE) spacecraft [Zwickl et al., 1998].

[9] The PLASLIFE code, developed at Aberystwyth University, was used to assist in the interpretation of ionospheric observations. The code calculates the electron density of a volume of plasma at the $F$-layer peak at $1 \mathrm{~s}$ intervals. As a starting point an initial value for the electron density of this volume is required as input. The subsequent rate of change of plasma density in this volume depends on driving parameters: solar flux, solar zenith angle, thermospheric composition, optical depth of the atmosphere, ion temperature, neutral 
temperature, and relative velocity of the ion and the neutral species. Each of these can be varied and chosen to be representative of estimated conditions. The relative importance of the parameters driving the changes in the plasma density can thus be investigated by varying any one parameter, or combination of parameters, while keeping others constant. In this study all parameters, with the exception of the solar flux, were varied in turn.

[10] In the PLASLIFE code, plasma production by photoionization is calculated using the Lambert-Beer law [Rees, 1989]. The solar EUV spectrum at the top of the atmosphere is given by the solar EUV flux model for aeronomic calculations (EUVAC), with the attenuation at the different wavelengths on the transionospheric paths based on the photoionization and photoabsorption cross sections of Richards et al. [1994a, 1994b]. Plasma loss is due to dissociative recombination, the rate of which is governed by the reactions of $\mathrm{O}^{+}$with $\mathrm{N}_{2}$ and $\mathrm{O}_{2}$. Several recombination coefficients are available and PLASLIFE uses those of Hierl et al. [1997], as these have been shown to give the best agreement compared to ionospheric observations [Mikhailov and Schlegel, 2000]. The values of the driving parameters in a given run of the code are changed with time. This is done by setting appropriate values for the parameters at the start time and the end time of the interval of interest and allowing their values to ramp linearly between these during the simulation. Naturally, if a parameter was the same at the start and end time, then this parameter was constant throughout the run, as, for example, in the case of the solar flux. Plasma transport is not explicitly included in the code. However, locations for the plasma volume at the start and end of the time of interest are chosen based on the high-latitude convection pattern, and the parameters are ramped linearly in time between their values at these locations. In the present study the high-latitude convection patterns inferred from the SuperDARN are used to assist in the choice of the start location, end location, and duration of simulation. This is demonstrated in section 5 .

[11] PLASLIFE was tested by comparison with data from the Chilton ionosonde $\left(51.7^{\circ} \mathrm{N}, 358.8^{\circ} \mathrm{E} ; 48.2^{\circ} \mathrm{MLAT}, 77.5^{\circ}\right.$ MLON) during winter, summer, and equinox at both solar minimum and solar maximum. This midlatitude station was chosen, as horizontal transport was not significant and, so, could be neglected. Therefore observations at the same location could be directly compared with the model. In the simulation the observed electron density at a given time was used as input and the modeled value at a later time agreed with the observed value, within experimental uncertainties. Further tests at high latitudes, specifically to investigate the role of photoionization at solar zenith angles of $>90^{\circ}$, were undertaken using the EISCAT radars. In these tests EISCAT observed at multiple locations that were aligned with the plasma flow. The observed electron density value at the upstream location corresponding to the start time of the run was used as input. The modeled and observed values at the final location were compared and agreed within experimental uncertainties. PLASLIFE had also been used previously to assist in the interpretation of observations in the nightside ionosphere [Pryse et al., 2006; Wood et al., 2008].

[12] The modular form of the code means that PLASLIFE can readily be adapted to represent other situations. It is currently being modified for the Venusian ionosphere; the required developments and this specific application are discussed in a subsequent paper.

\section{Data Selection}

[13] The nightside high-latitude ionosphere of the European sector forms the focus of this study, with the electron density measurements recorded above Svalbard around solar maximum between 1 January 1999 and 31 December 2001. Observations conducted by the ESR were used and the EISCAT catalog at Rutherford Appleton Laboratory was the starting point for this analysis. Initially measurements in the night sector were selected, with the time restricted to between 1900 and 2300 UT to cover local magnetic midnight ( 2040 UT at the location of the radar). Data from both the ESR $42 \mathrm{~m}$ dish and the ESR $32 \mathrm{~m}$ dish were considered. All measurements from the former were used; the radar beam of this dish was permanently aligned along the geomagnetic field line in the $F$ region. Data from the $32 \mathrm{~m}$ dish were considered only if the beam was in a position such that the ionospheric intersection at an altitude of $350 \mathrm{~km}$ was within a horizontal distance of $100 \mathrm{~km}$ of the $42 \mathrm{~m}$ dish field-aligned radar beam. This ensured that the observations were all from within a spatial region of scale comparable to the horizontal dimension of a polar patch. A total of 69 data sets were initially identified.

[14] The data from each of the 69 sets were then considered in view of specific selection criteria to determine whether the conditions were favorable for polar cap patches. The criteria are described below and an example is presented in section 4 to illustrate how they are applied. For the first criterion, highlatitude electric potential patterns inferred from the SuperDARN were used to establish if the plasma flowed from the polar cap into the nightside and, if so, the time at which the ESR was in a location suitable to observe the plasma in the antisunward flow. The time at which the $350 \mathrm{~km}$ ionospheric intersection of the ESR beam was at the midpoint between the $+3 \mathrm{kV}$ and the $-3 \mathrm{kV}$ contours of the dawn and dusk cells, respectively, was determined and this was used as a proxy for the midpoint of antisunward cross-polar flow. Data were then selected from a $3 \mathrm{~h}$ interval centered on this time. This ensured that the ESR observations used in the study were within a region where plasma was expected to have been drawn across the polar cap. The second selection criterion was based on the relative position of the convection reversal boundary $(\mathrm{CRB})$ and the ESR observations. The CRB was identified from the high-latitude convection patterns inferred from the SuperDARN as detailed in section 4. If the latitude of the CRB was higher than that of the ESR when the longitudes were the same, then the data for these specific times were excluded. This was to remove the possibility of precipitation in the auroral zone modifying the plasma densities. The third selection criterion was also to exclude the possibility of modification of the plasma densities by in situ precipitation. Particle precipitation increases electron densities in the $E$ region and so, if the electron density at an altitude of $125 \mathrm{~km}$ was increased from the background level by more than $400 \%$, these specific data points were excluded. A value of $400 \%$ was chosen by inspection of the data, as this was a clear indicator of precipitation in all of the data sets considered. The background level was set to the median value of the electron density at the $125 \mathrm{~km}$ altitude for the data set as 


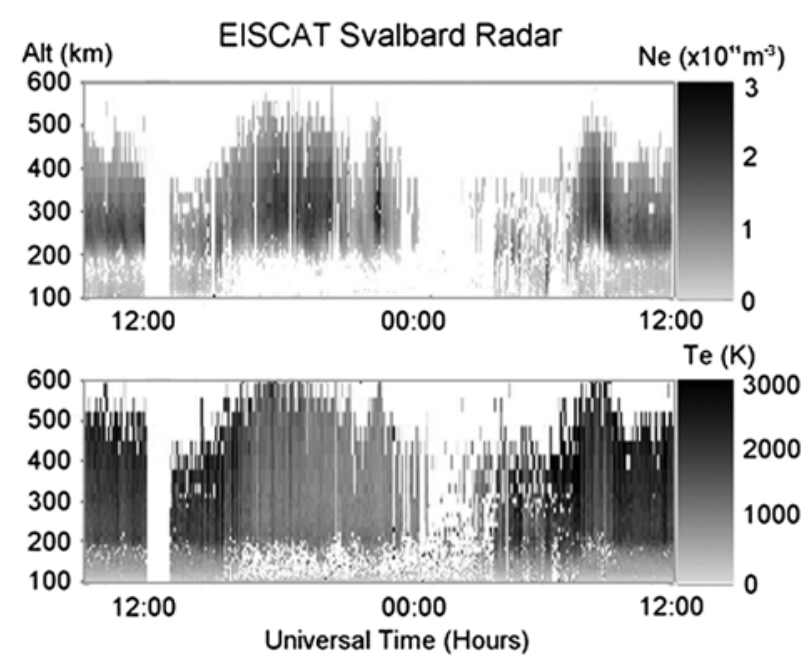

Figure 1. Electron densities (top) and electron temperatures (bottom) observed by the $32 \mathrm{~m}$ dish of the European Incoherent Scatter (EISCAT) Svalbard Radar along the geomagnetic field at an azimuth of $-179.4^{\circ}$ and an elevation of $81.6^{\circ}$ between 0900 UT on 9 February 1999 and 1200 UT on 10 February 1999.

determined from the first and second selection criteria. The final criterion was that IMF $B_{z}$ was predominantly negative. Data from the ACE spacecraft commencing $2 \mathrm{~h}$ before the first ESR observation used in each data set and terminating $1 \mathrm{~h}$ before the final ESR observation were considered. IMF $B_{z}$ was taken to be predominantly negative if its mean value within this time interval was less than $-0.5 \mathrm{nT}$ and the $B_{z}$ component was negative for at least $67 \%$ of the data points. Eighteen data sets met all selection criteria and these were used in the study. None of the selection criteria were based on the $F$-region electron densities.

\section{Observations}

[15] To illustrate the method outlined in section 3 the data set between 0900 UT on 09 February 1999 and 1200 UT on 10 February 1999 was considered and the analysis of these data is presented as an example of how all 18 data sets were individually processed. This example was chosen solely because it is the first when the sets are listed in chronological order. The electron densities and temperatures measured by the $32 \mathrm{~m}$ dish of the ESR observing along the magnetic field line in the $F$ region (azimuth, $-179.4^{\circ}$; elevation, $81.6^{\circ}$ ) for this data set are shown in Figure 1. A preliminary look at these data showed an electron density enhancement in the magnetic evening sector seen between 1700 and 2200 UT on 09 February 1999 that was likely to be of particular interest. This was associated with relatively low electron temperatures of $(1000 \pm 200) \mathrm{K}$, which ruled out in situ precipitation as the plasma source. The relatively high peak altitude of the electron density of $\sim 350 \mathrm{~km}$, where recombination rates are relatively low, suggested that the plasma was long-lived.

[16] Observations by the SuperDARN coincident with the electron density enhancement showed that the high-latitude convection pattern was dominated by two large convection cells that would draw plasma antisunward from near local noon into the nightside ionosphere. The plots in Figure 2, at 30 min intervals, show the electric potential patterns during the time when the ESR was transversing the Harang discontinuity. The number of backscatter measurements in the magnetic midnight sector was not large but was sufficient to identify the regions of antisunward flow. The ionospheric intersection of the ESR beam at an altitude of $350 \mathrm{~km}$, shown by the cross in each plot in Figure 2, was in a region of antisunward cross-polar cap flow and poleward of the CRB, indicated by the gray line perpendicular to the equipotential contours throughout the interval. The ESR beam at this altitude was coincident with the midpoint of the $+3 \mathrm{kV}$ and $-3 \mathrm{kV}$ contours at (1936 \pm 0015$)$ UT, with the uncertainty arising as a consequence of inevitable small-scale variation in the convection pattern. Data were therefore considered between 1806 and $2106 \mathrm{UT}$, a $3 \mathrm{~h}$ window centered on $1936 \mathrm{UT}$. Observations between 1825 and 1827 UT were excluded because of enhanced electron densities at an altitude of $125 \mathrm{~km}$, which were a possible signature of local precipitation. IMF $B_{z}$ observed by the ACE spacecraft between 1606 and 2006 UT was predominantly negative. It had a mean value of $-1.7 \mathrm{nT}$, and $98 \%$ of the data points observed took negative values.

[17] The mean value of the largest $25 \%$ of the electron density measurements at $350 \mathrm{~km}$ in the data set (but excluding 125 UT to $18: 27$ UT) was $(1.9 \pm 0.1) \times 10^{11} \mathrm{~m}^{-3}$, and this was set as the patch level. Any precipitation within the polar cap was unlikely to have had a significant effect on the patch densities, as Buchau et al. [1983] showed that the maximum densities that could be produced by soft particle precipitation were significantly lower than those observed in polar cap patches. A background ionospheric density was established where the ESR was close to the center of the dawn cell and well removed from the strong antisunward flow. In this example the region was between 2300 and 2330 UT and the mean electron density at an altitude of $350 \mathrm{~km}$ was $(0.6 \pm 0.1) \times 10^{11} \mathrm{~m}^{-3}$, giving a patch-to-background ratio of $3.0 \pm 0.4$.

[18] The patch-to-background ratios calculated for each of the 18 data sets are shown in Figure 3 as a function of the number of days from winter solstice. This measure, rather than day of the year, was chosen so that observations from spring and autumn could be presented together. The patch-tobackground ratios exhibit two clear populations. In the first interval, between 50 and 78 days from winter solstice, the patch-to-background ratios varied between $1.4 \pm 0.5$ and $9.4 \pm 2.9$. The majority were $>2$ and were therefore consistent with the criteria for a polar cap patch proposed by Crowley [1996]. The second regime is close to summer solstice, between day 161 and day 173. In this interval the patch-tobackground ratios ranged between $1.3 \pm 0.1$ and $1.9 \pm 0.2$, illustrating the presence of enhanced electron density associated with cross-polar cap flow but not fulfilling the definition of a polar cap patch. In addition to these two regimes, there were also observations close to winter solstice on 12 December 2001 when a patch-to-background ratio of $8.5 \pm 2.0$ was recorded. The absence of data between 80 and 160 days from winter solstice is a consequence of the lack of observations rather than any physical effect.

[19] The analysis was repeated using an alternative definition of the background plasma density. This was set using the mean value of the lowest $25 \%$ of the electron density data values at $350 \mathrm{~km}$ during the $3 \mathrm{~h}$ window identified from the 


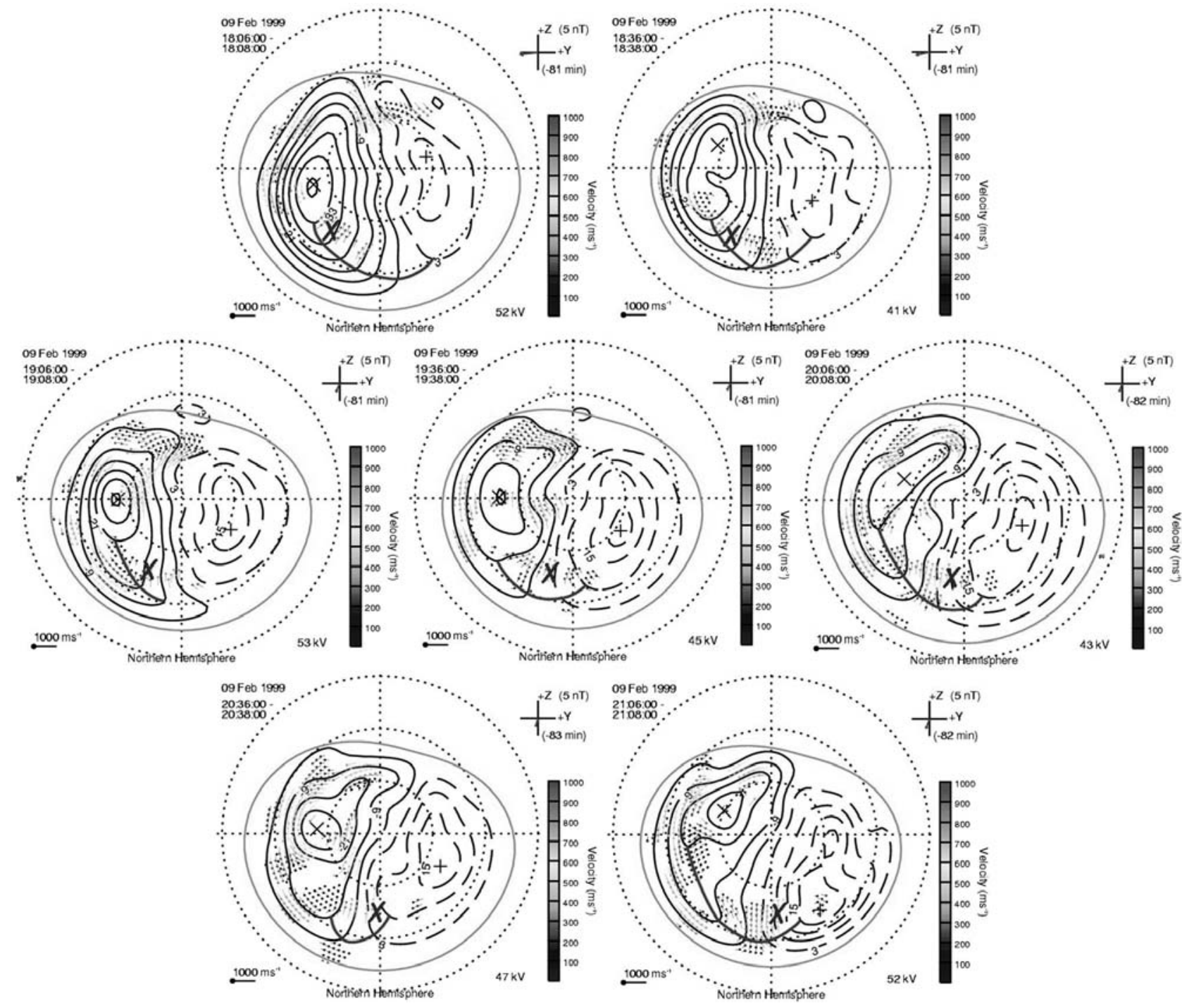

Figure 2. Super Dual Auroral Radar Network (SuperDARN) electric potential patterns at 30 min intervals between 1806 and 2106 UT on 9 February 1999 as a function of geomagnetic latitude (MLAT) and magnetic local time. Magnetic noon is at the top of each plot, with dusk and dawn on the left- and right-hand sides, respectively. MLAT is indicated by the dotted (gray) circular lines at $10.0^{\circ}$ increments, with $60.0^{\circ}$ MLAT at the outer circumference and the magnetic pole at the center of each panel. The cross in each plot represents the ionospheric intersection of the EISCAT Svalbard Radar beam at an altitude of $350 \mathrm{~km}$, and the thick gray line perpendicular to the equipotential contours represents the convection reversal boundary.

SuperDARN electric potential patterns. This was the same time interval from which the patch density was set as the largest $25 \%$ of the electron density data points at this altitude. The same two clear populations were observed, however, the patch-to-background ratios were approximately $40 \%$ lower. The analysis was also repeated at the altitude of the $F$-layer peak, rather than $350 \mathrm{~km}$. The revised value of the patch-tobackground ratio lay within the standard deviation of the value at $350 \mathrm{~km}$ in every case.

\section{Discussion}

[20] Patch-to-background ratios observed between winter and equinox were between $1.4 \pm 0.5$ and $9.4 \pm 2.9$, while in summer they were between $1.3 \pm 0.1$ and $1.9 \pm 0.2$. This study was conducted between 1999 and 2001, close to solar maximum. The observations between winter and equinox were consistent with Pedersen et al. [1998], who reported patchto-background ratios of up to 9 in the polar winter ionosphere close to solar maximum. Observations from the present study also encompassed the patch-to-background ratio of 3 modeled in the winter nightside ionosphere by Sojka et al. [1994]. However, the observed patch-to-background ratios in summer were significantly larger than the few tenths of a percent modeled by Sojka et al. [1994].

[21] PLASLIFE was used to simulate the patch-to-background ratios at monthly intervals. The initial plasma density was estimated from the international reference ionosphere (IRI) [Bilitza, 1990, 2001] at an altitude of $350 \mathrm{~km}$ at $65^{\circ} \mathrm{N}$, $260^{\circ} \mathrm{E}$, at local magnetic noon. This was used to represent the 


\section{Seasonal variation of patch-to-background ratio}

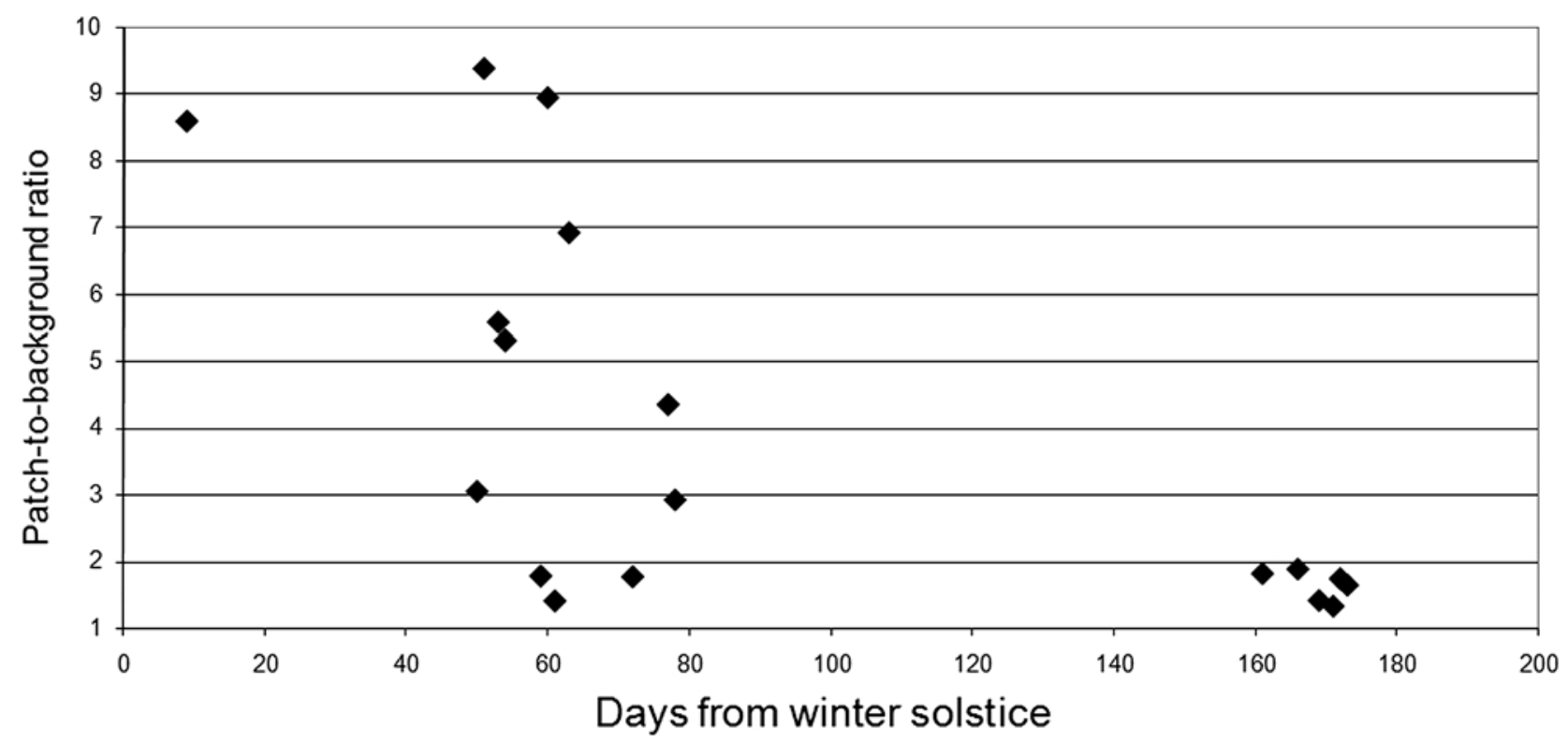

Figure 3. Patch-to-background ratios as a function of the number of days from winter solstice for observations made between 1999 and 2001. When the patch-to-background ratio is $<2$, these enhancements are not formally defined as polar cap patches.

plasma on the dayside entrained into the high-latitude convection pattern. SuperDARN electric potential maps indicated that plasma was transported at a velocity of about $600 \mathrm{~m} \mathrm{~s}^{-1}$ from this sector to the location of the ESR in some $2 \mathrm{~h}$. Ion temperatures were also obtained from IRI; neutral temperatures and velocities were taken from a statistical study close to the geomagnetic pole at Thule, Greenland $\left(76.5^{\circ} \mathrm{N}, 68.4^{\circ} \mathrm{W} ; 85.0^{\circ} \mathrm{MLAT}, 32.7^{\circ} \mathrm{MLON}\right)$ [Killeen et al., 1995]; and the thermospheric composition, specifically the number densities of molecular nitrogen, molecular oxygen, and atomic oxygen, were taken from Mass Spectrometer Incoherent Scatter model [Hedin, 1991]. The $F_{10.7}$ solar flux was set as 180 solar flux units, the average value of this parameter during the year 2000. The background plasma density in the nightside ionosphere was set to the monthly mean obtained from IRI at the location of the ESR at 23:00 UT.

[22] Calculated patch-to-background ratios for each month are shown in Figure 4. A clear trend of higher patch-tobackground ratios in winter and lower values in summer was simulated, with the highest patch-to-background ratio of $3.0 \pm 0.9$ obtained in December and the lowest value of $1.1 \pm$ 0.4 in June. Patch-to-background ratios between March and September were $<2$, so they could not be formally defined as patches. The trend was consistent with the observations (Figure 3), however, the modeled values were lower than those observed. This difference was, in part, a consequence of the model's representing average conditions rather than extreme values. The patch-to-background ratios given in the previous modeling study by Sojka et al. [1994] were also lower than the maximum values observed by Pedersen et al. [1998]. The results from PLASLIFE may also be influenced by the assumption in the simulation that plasma was drawn from local noon, whereas higher-density plasma can be entrained into the high-latitude convection pattern from the postnoon sector [Weber et al., 1984; Pryse et al., 2004]. This restricted ability to model the absolute value of the patch-to-background ratio does not detract from the capability of this simulation to determine the relative differences across seasons and hence identify physical processes that are likely to be responsible for this variation.

[23] The simulated patch-to-background ratios for the nightside ionosphere depended on the initial electron density, the background plasma density, and the driving parameters: the thermospheric composition, the optical depth of the atmosphere, the temperatures of the ion and neutral species, the relative velocity of the ion and neutral species, the solar flux, and the solar zenith angle. Each of these varied between winter and summer, with the exception of the solar flux, for which an average value for the year was taken. To establish the relative importance of the role of these parameters, the December simulation was repeated seven times, with values swapped with those used in the June simulation in each case; the results are reported in Table 1. December and June were chosen, as they gave the highest and lowest modeled patchto-background ratios, respectively. When the June thermospheric composition was used the patch-to-background ratio fell from $3.0 \pm 0.9$ to $1.4 \pm 0.4$, the largest change in this ratio. This variation was due to the greater number densities of molecular nitrogen and oxygen, which enhanced the plasma loss rate, while the reduction in the number density of atomic oxygen reduced photoionization. The thermospheric composition in summer resulted from upwelling in the sunlit summer polar cap [Schunk and Sojka, 1987], reducing the ratio of atomic oxygen to molecular nitrogen and molecular oxygen. To investigate the effect of the electron densities 


\section{Calculated seasonal variation of patch-to-background ratio}

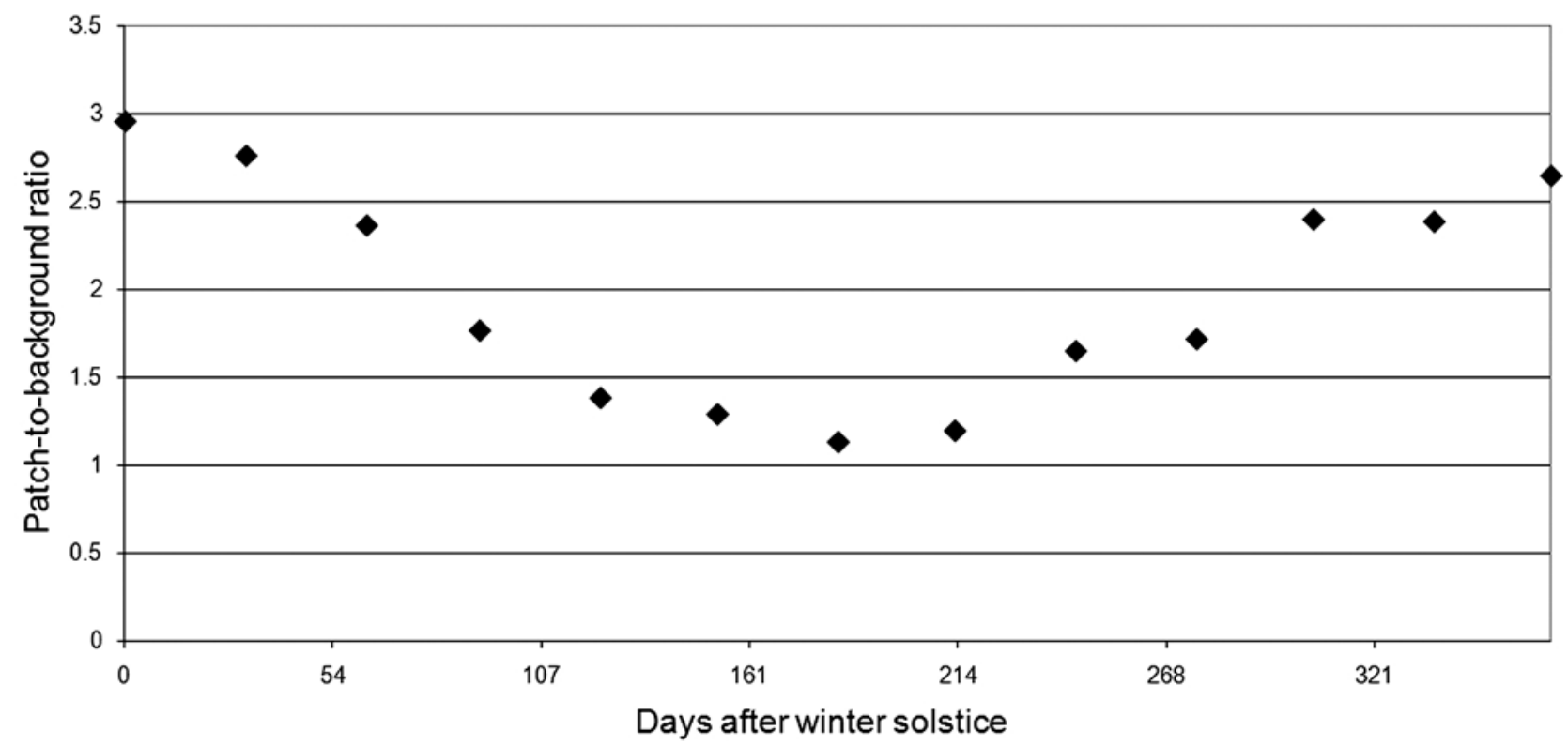

Figure 4. Simulated patch-to-background ratios from the PLASLIFE (PLASma LIFEtime) code for the location of the EISCAT Svalbard Radar at magnetic midnight at monthly intervals between 21 December 1999 and 21 December 2000.

drawn into the polar cap, the initial plasma density was changed. The plasma densities drawn into the polar cap were higher in winter than in summer by a factor of $\sim 2$, and when the lower initial plasma density from the June simulation was used, the patch-to-background ratio in the nightside ionosphere fell substantially, to $1.7 \pm 0.5$. The underlying cause for change in the initial plasma density is naturally the thermosphere [Hargreaves, 1992], although this is not explicitly accommodated in the thermospheric composition in the code.

[24] Variation in other driving parameters also influenced the patch-to-background ratio, although these effects were less significant than the changes already discussed. The background plasma density had a significant effect on the patch-to-background ratio, and when the June value was used in the December simulation this ratio was reduced to $2.3 \pm$ 0.7 . The greater background plasma density in the June simulation was due to the maintenance of the plasma in the summer polar cap by photoionization. The solar zenith angle also affected the patch-to-background ratio by altering the position of the solar terminator, which determined whether sunlight was present to cause photoionization within the patch. However, when using the June value in the December simulation it transpired that there was no significant effect on either the plasma density or the patch-to-background ratio in the nightside ionosphere. In this instance the increased photoionization obtained with the June solar zenith angle increased the plasma density, but this greater density also enhanced the plasma loss rate. The greater ion and neutral temperatures that occurred in June enhanced the plasma loss rate when used in the December simulation, although this only reduced the patch-to-background ratio to values of $2.9 \pm$ 0.9 and $2.8 \pm 0.9$, respectively. The optical depth of the atmosphere altered the intensity of the solar EUV radiation at an altitude of $350 \mathrm{~km}$ and hence influenced plasma production by photoionization. The seasonal variation in this parameter had only a small influence on the patch-to-background ratio, and when the June optical depth was used in the winter simulation the ratio was reduced to $2.7 \pm 0.9$.

\section{Conclusions}

[25] The influence of the season on the patch-to-background density ratio of polar cap patches in the nightside ionosphere was observed above northern Scandinavia around solar maximum. This is the first time that the seasonal influence on the plasma has been investigated in this region.

Table 1. The Influence of Seasonal Changes in Thermospheric Composition, Initial Plasma Density, Background Plasma Density, Solar Zenith Angle, Ion Temperature, Neutral Temperature and Optical Depth on the Patch-to-Background Ratio Simulated Using the PLASLIFE Code

\begin{tabular}{lc}
\hline \multicolumn{1}{c}{ Simulation } & Patch-to-Nightside Ratio \\
\hline 21 Dec & $3.0 \pm 0.9$ \\
21 Dec, thermospheric composition & $1.4 \pm 0.4$ \\
from 21 Jun & $1.7 \pm 0.5$ \\
21 Dec, initial plasma density from & \\
21 Jun & $2.3 \pm 0.7$ \\
21 Dec, background plasma density & $3.0 \pm 0.9$ \\
from 21 Jun & $2.9 \pm 0.9$ \\
21 Dec, solar zenith angle from 21 Jun & $2.8 \pm 0.9$ \\
21 Dec, ion temperatures from 21 Jun & \\
21 Dec, neutral temperatures from & $2.7 \pm 0.9$ \\
21 Jun & $1.1 \pm 0.4$ \\
21 Dec, optical depth from 21 Jun & \\
21 Jun &
\end{tabular}


The night sector is particularly significant, as it is the region within the polar cap where the patches are farthest from their source and have the longest time to decay. In the majority of winter cases in the study undertaken, patches observed had a patch-to-background ratio $>2$ and were therefore consistent with the definition of a polar cap patch. In summer clear electron density enhancements were seen in the nightside ionosphere, but the patch-to-background ratio was $<2$. While these enhancements could not formally be called patches, it was clear that the high-latitude convection pattern was responsible for transporting significant electron density enhancements into the nightside ionosphere. This suggests that there could be significant structuring within the nightside ionosphere in all seasons, a result that is likely to be of interest for radio propagation applications. Previous studies have shown that patches can exit the polar cap and form boundary blobs in the nightside auroral oval in winter. The next logical step in these studies would be to establish whether this effect can also be observed in summer.

[26] The variation in the patch-to-background ratio between winter and summer was modeled using the PLASLIFE computer simulation, and the reasons for the summer-towinter differences were established. These were primarily variation in the chemical composition of the atmosphere, which, in summer, both reduced the plasma density drawn into the polar cap and enhanced plasma loss by recombination. A secondary factor was the maintenance of the background plasma density in summer by photoionization throughout the polar cap. Taken collectively, these results show that the thermosphere and ionosphere must be viewed as a coupled system, and it is essential that further studies of thermospheric-ionospheric coupling are undertaken.

[27] Acknowledgments. Financial support for this project was provided by the UK Science and Technology Facilities Council under grant $\mathrm{PP} / \mathrm{E} 001157 / 1$. EISCAT is an international facility supported by the national science councils of China, Finland, France, Germany, Japan, Norway, Sweden, and the United Kingdom. The SuperDARN facility is funded by the National Research Programs of Australia, Canada, Finland, Japan, South Africa, Sweden, the United Kingdom, and the United States, and the electric potential map data were provided by Tim Yeoman and Adrian Grocott at the University of Leicester. The IMF data were provided by N. Ness and obtained from the CDAWeb. A.G.W. acknowledges receipt of a STFC postgraduate studentship.

[28] Robert Lysak thanks Michael A. Hapgood and Lie Zhu for their assistance in evaluating the manuscript.

\section{References}

Bilitza, D. (1990), International Reference Ionosphere 1990, NSSDC 90-22, Greenbelt, Md.

Bilitza, D. (2001), International Reference Ionosphere 2000, Radio Sci., 36, 261-275, doi:10.1029/2000RS002432.

Bowline, M. D., J. J. Sojka, and R. W. Schunk (1996), Relationship of theoretical patch climatology to polar cap patch observations, Radio Sci., 31, 635-644, doi:10.1029/96RS00236.

Buchau, J., and B. W. Reinisch (1991), Electron density structures in the polar F region, Adv. Space Res., 11(10), 29-37, doi:10.1016/02731177(91)90317-D

Buchau, J., B. W. Reinisch, E. J. Weber, and J. G. Moore (1983), Structure and dynamics of the winter polar cap $\mathrm{F}$ region, Radio Sci., 18 , 995-1,010.

Chisham, G., et al. (2007), A decade of the Super Dual Auroral Radar Network (SuperDARN): Scientific achievements, new techniques and future directions, Surv. Geophys., 28, 33-109, doi:10.1007/s10712007-9017-8.

Coley, W. R., and R. A. Heelis (1998), Structure and occurrence of polar ionization patches, J. Geophys. Res., 103(A2), 2201-2208, doi:10.1029/97JA03345.
Crowley, G. (1996), Critical review of patches and blobs, in Polar Cap Boundary Phenomena, URSI Review of Radio Science 1993-1996, edited by W. R. Stone, pp. 619-648, Oxford Univ. Press, Oxford, UK.

Foster, J. C. (1984), Ionospheric signatures of magnetospheric convection, J. Geophys. Res., 89, 855-865, doi:10.1029/JA089iA02p00855.

Greenwald, R. A., et al. (1995), SuperDARN: A global view of the dynamics of high-latitude convection, Space Sci. Rev., 71, 761-796, doi:10.1007/BF00751350.

Hargreaves, J. K. (1992), The Solar-Terrestrial Environment, Cambridge Atmospheric and Space Science Series, Cambridge Univ. Press, Cambridge, UK.

Hedin, A. E. (1991), Extension of the MSIS thermospheric model into the middle and lower atmosphere, J. Geophys. Res., 96, 1159-1172, doi:10.1029/90JA02125.

Hierl, P. M., I. Dotan, J. V. Seeley, J. M. Van Doren, R. A. Morris, and A. A. Viggiano (1997), Rate constants for the reactions of $\mathrm{O}^{+}$with $\mathrm{N} 2$ and $\mathrm{O} 2$ as a function of temperature $(300-1800 \mathrm{~K}), \mathrm{J}$. Chem. Phys., 106, 3540-3544, doi:10.1063/1.473450.

Killeen, T. L., Y.-I. Won, R. J. Niciejewski, and A. G. Burns (1995), Upper thermosphere winds and temperatures in the geomagnetic polar cap: Solar cycle, geomagnetic activity, and interplanetary magnetic field dependencies, J. Geophys. Res., 100, 21,327-21,342, doi:10.1029/ 95JA01208.

McEwen, D. J., and D. P. Harris (1996), Occurrence patterns of F layer patches over the north magnetic pole, Radio Sci., 31, 619-628, doi:10.1029/96RS00312.

Mikhailov, A. V., and K. Schlegel (2000), A self-consistent estimate of $\mathrm{O}^{+}+\mathrm{N}_{2}$-rate coefficient and total EUV solar flux with $\lambda<1050 \AA$ using EISCAT observations, Ann. Geophys., 18, 1164-1171.

Moen, J., N. Gulbrandsen, D. A. Lorentzen, and H. C. Carlson (2007), On the MLT distribution of $F$ region polar cap patches at night, Geophys. Res. Lett., 34, L14113, doi:10.1029/2007GL029632.

Pedersen, T. R., B. G. Fejer, R. A. Doe, and E. J. Weber (1998), Incoherent scatter radar observations of horizontal $\mathrm{F}$ region plasma structure over Sondrestrom, Greenland, during polar cap patch events, Radio Sci., 33, 1847-1866, doi:10.1029/98RS01702.

Pedersen, T. R., B. G. Fejer, R. A. Doe, and E. J. Weber (2000), An incoherent scatter radar technique for determining two-dimensional horizontal ionization structure in polar cap $F$ region patches, $J$. Geophys. Res., 105, 10,637-10,656, doi:10.1029/1999JA000073.

Pryse, S. E., R. W. Sims, J. Moen, L. Kersley, D. Lorentzen, and W. F. Denig (2004), Evidence for solar-production as a source of polar-cap plasma, Ann. Geophys., 22, 1093-1102.

Pryse, S. E., A. G. Wood, H. R. Middleton, I. W. McCrea, and M. Lester (2006), Reconfiguration of polar-cap plasma in the magnetic midnight sector, Ann. Geophys., 24, 2201-2208.

Rees, M. H. (1989), Physics and Chemistry of the Upper Atmosphere, Cambridge Atmospheric and Space Science Series, Cambridge Univ. Press, Cambridge, UK

Reiff, P. H., and J. L. Burch (1985), IMF $B_{y}$-dependent plasma flow and birkeland currents in the dayside magnetosphere 2. A global model for northward and southward IMF, J. Geophys. Res., 90, 1595-1609, doi:10.1029/JA090iA02p01595

Richards, P., J. Fennelly, and D. Torr (1994a), EUVAC: A solar EUV flux model for aeronomic calculations, J. Geophys. Res., 99, 8981-8992, doi:10.1029/94JA00518.

Richards, P., J. Fennelly, and D. Torr (1994b), Correction to "EUVAC: A Solar EUV Flux Model for Aeronomic Calculations," J. Geophys. Res., 99, 13,283-13,283, doi:10.1029/94JA01446.

Risbeth, H., and C. S. G. K. Setty (1961), The F-layer at sunrise, J. Atmos. Terr. Phys., 21, 263-276, doi:10.1016/0021-9169(61)90205-7.

Robinson, R. M., R. T. Tsunoda, and J. F. Vickrey (1985), Sources of $F$ region ionisation enhancements in the nighttime auroral zone, J. Geophys. Res., 90, 7533-7546, doi:10.1029/JA090iA08p07533.

Ruohoniemi, J. M., and R. A. Greenwald (2005), Dependencies of highlatitude plasma convection: Consideration of interplanetary magnetic field, seasonal, and universal time factors in statistical patterns, J. Geophys. Res., 110, A09204, doi:10.1029/2004JA010815.

Schunk, R. W., and J. J. Sojka (1987), A theoretical study of the lifetime and transport of large ionospheric density structures, J. Geophys. Res., 92, 12,343-12,351, doi:10.1029/JA092iA11p12343

Sojka, J. J., M. D. Bowline, and R. W. Schunk (1994), Patches in the polar ionosphere: UT and seasonal dependence, J. Geophys. Res., 99, 14,95914,970, doi:10.1029/93JA03327.

Tsunoda, R. T. (1988), High-latitude F region irregularities: A review and synthesis, Rev. Geophys., 26, 719-760, doi:10.1029/RG026i004p00719.

Wannberg, G., et al. (1997), The EISCAT Svalbard radar: A case study in modern incoherent scatter radar system design, Radio Sci., 32, 2283 2308, doi:10.1029/97RS01803 
Weber, E. J., J. Buchau, J. G. Moore, J. R. Sharber, R. C. Livingston, J. D. Winningham, and B. W. Reinisch (1984), $F$ layer patches in the polar cap, J. Geophys. Res., 89, 1683-1694, doi:10.1029/JA089iA03p01683.

Weber, E. J., J. A. Klobuchar, J. Buchau, H. C. Carlson Jr., R. C. Livingston, O. de la Beaujadiere, M. McCready, J. G. Moore, and G. J. Bishop (1986), Polar cap $F$ layer patches: Structure and dynamics, J. Geophys. Res., 91, 12,121-12,129, doi:10.1029/JA091iA11p12121.

Wood, A. G., S. E. Pryse, H. R. Middleton, and V. S. C. Howells (2008), Multi-instrument observations of nightside plasma patches under conditions of IMF Bz positive, Ann. Geophys., 26, 2203-2216.
Wright, J. W. (1963), The $F$ region seasonal anomaly, J. Geophys. Res., 68 , $4379-4381$.

Zwickl, R. D., et al. (1998), The NOAA Real-Time Solar-Wind (RTSW) system using ACE data, Space Sci. Rev., 86, 633-648, doi:10.1023/ A:1005044300738.

S. E. Pryse and A. G. Wood, Aberystwyth University, Aberystwyth, Ceredigion SY23 2AX, United Kingdom. (alan.wood@aber.ac.uk) 